\title{
Effect of wormcast on phenolic acids and microbes in the Rehmannia glutinosa succession cropping soils
}

\author{
Yupeng $\mathrm{He}^{1,2, \mathrm{a}}$, Nianxi Zhao ${ }^{3, \mathrm{~b}}$, Hongpeng Yang ${ }^{2, \mathrm{c}}$, Jinlong Wang ${ }^{2, \mathrm{~d}}$, Xidong \\ $\mathrm{Wu}^{2, \mathrm{e}^{*}}$ \\ ${ }^{1}$ College of Agriculture \& Biotechnology, Zhejiang University, Hangzhou, China \\ ${ }^{2}$ College of Agronomy \& Resources and Environment, Tianjin Agriculture University, Tianjin,China \\ ${ }^{3}$ College of Life Science, Nankai University, Tianjin, China \\ ahebobo329light@163.com, bzhaonianxi@nankai.edu.cn ,cyanghongpeng2003@163.com, \\ dwangjinlong@tjau.edu.cn, ${ }^{\mathrm{e}}$ wuxidong@tjau.edu.cn( ${ }^{*}$ Corresponding author)
}

Keywords: Wormcast; Continuous cropping obstacle; Rehmannia glutinosa; Phenolic acid; Microbe Abstract. In this paper, different proportion of wormcast was added to the Rehmannia glutinosa continuous cropping soils including first and second stubble to adjust the phenolic acids content and microbial biomass and improve the soil environment after continuous cropping. Results showed that vanillic acid, vanillin and ferulic acid in the soils cropped Rehmannia glutinosa for one year were all somewhat decreased after a growth cycle, half a year. The ratio of fungi to bacteria was firstly increased then decreased in the soils cropped Rehmannia glutinosa for one year, while an opposite result in the second stubble soil after addition of wormcast. Taken together, the effect, 10 percent addition of wormcast to the soil cropped Rehmannia glutinosa for two years, was the best.

\section{Introduction}

Rehmannia glutinosa L. is a perennial herbaceous species belonging to the Scrophulariaceae family, and is widely cultivated in Henan, Shanxi, Shandong, Anhui, and Jilin Province in China. The medicinal value of Rehmannia glutinosa was recorded and narrated in Sheng Nong's herbal classic, the earliest medicine monographs in China. Modern research showed that Rehmannia glutinosa, which belongs to commonly used Chinese medicinal herbs, has the functions of regulating blood sugar, protecting liver, hemostasis, diuresis, antiphlogosis and so on. It's root and processed products were often used medicinally ${ }^{[1]}$. It has been an accepted fact for hundreds of years that Rehmannia glutinosa can't be cultured without rotation. Easing the Rehmannia glutinosa continuous cropping obstacle has become a hot spot problem in the world because of the large demand and limited suitable planting regions.

Some researchers found that phenolic acids secreted from Rehmannia glutinosa were the key causes of continuous cropping obstacles. ${ }^{[2]}$ Meanwhile, rhizosphere microecological imbalance may be the key factor in causing Rehmannia glutinosa continuous cropping obstacles, which has been proved by many researchers ${ }^{[3-5]}$. The addition of wormcast to the soils that had cropped cucumbers could relieve the continuous cropping obstacle. The reasons were wormcast could not only increase the ratio of bacteria to fungus, improve the soil fertility ${ }^{[6]}$, but also could adsorb allelochemicals excreted from plant roots, remove adverse influences caused by allelochemicals ${ }^{[7]}$, and the meanwhile, some antagonistic microbe in wormcast could restrain the grow of pathogenic bacteria. ${ }^{[7,]}$ But there is no research about whether wormcast could improve the rhizospheric microorganism environment and the number of beneficial bacterium of rehmannia continuous cropping soils

Therefore, wormcast was added in the continuous cropping soils in this paper to try to adjust phenolic acids content and microbial biomass and improve continuous cropping soil environment.

\section{Materials and Methods}

\section{Materials}

The soils used in this experiment were all half silty loam, including ones cropped Rehmannia glutinosa for one and two years, and ones had never cropped rehmannia. The soils were all taken from 
Yuncheng, Shanxi Province in China. Wormcast was bought from Jia LiMing Earthworm Company in Tianjin Province.

\section{Experiment design}

Double factors random block was used in this experiment. The first factor was soil, including ones cropped rehmannia for one and two years and ones had never cropped rehmannia. The second factor was wormcast, including low addition amount (10\%, weight ratio with soil, the same as follows) and high addition amount (30\%). Each dosage of wormcast mixed evenly with soils cropped rehmannia for one and two years. Soil never cropped rehmannia did not do any treatment. There was a group in each kind of soils treated as control and never mixed with additives.

Poured the mixed soil into pots $(\mathrm{cm})$ and put the fitted gauze bag at the bottom of the pots in case of earth leakage. The soil weight of each pot was $2.535 \mathrm{~kg}$ contained exogenous additive. Water the soils regularly to keep the moist. All experiment was conducted in greenhouse of Naikai University from October 17, 2012 to April 28, 2013.

Determination method of phenolic acid

The content of phenolic acids in the soils were determined by HPLC ${ }^{[8,9]}$

Soil extracting method ${ }^{[8,9]}$

Soil samples $(20 \mathrm{~g})$ were homogenized with $20 \mathrm{ml} \mathrm{NaOH}(1 \mathrm{~mol} / \mathrm{L})$ in centrifuge tubes $(50 \mathrm{ml})$ and stable at room temperature for all night after being sonicated in an ultrasonic bath for $30 \mathrm{~min}$, and sonicated for another $30 \mathrm{~min}$ the next day before being centrifuged at 3000r/min for $20 \mathrm{~min}$ to get the supernatant. Concentrated hydrochloric acid $(12 \mathrm{~mol} / \mathrm{L})$ was added to the supernatant to decrease the $\mathrm{PH}$ to 2.5, then put the liquid at room temperature for 2 hours and centrifuged it to get rid of humic acid. The supernatant was extracted by same volume normal butanol 3 times. Extracts were combined and dried by rotary evaporator, and then dissolved by methanol to $2 \mathrm{ml}$ and filtered through organic membrane (0.45um), then a portion was injected onto the HPLC. The result was calculated by dry soil.

Instrument used in the experiment

The chromatographic system was Shimadzu LC-20AT HPLC which consisted of two LC-20AT infusion pumps, one SPD-M20A ultraviolet detector and a 20uL manual injector. Water Purification System was UPH-I-20L. Rotary evaporator was EYEL4OSB-2000 and ultrasonic bath was KH5200DB.

\section{Chromatographic condition}

The separation was achieved by using a $4.6 \times 250 \mathrm{~mm}$, 5um, 100A $\mathrm{C}_{18}$ column (Venusll XBP, Tianjin, China ) with a mobile phase consisting of NaAc $(0.01 \mathrm{~mol} / \mathrm{L})$, acetic acid, n-butyl alcohol and ammonium hydroxide, whose proportion was 100:0.15:2:0.05. The mobile phase was delivered at a flow rate of $0.7 \mathrm{ml} / \mathrm{min}$ and detected at $277 \mathrm{~nm}$. The injection volume was $5 \mathrm{uL}$.

Standard substance and reagent

The standard substances of ferulic acid, p-hydroxybenzoic acid and vanillic acid were all bought from Shiji Aoke Company in Beijing. Vanilline standard was bought from Xiya Company in Sichuan. The methanol and n-butyl alcohol used in the mobile phase were all chromatogram class. Glacial acetic acid was analytical reagent made in China. All the mobile phase and samples were filtered through millipore filters $(0.45 \mathrm{um})$.

Determination method of microbial biomass

Plate count method was used to determine the biomass of soil microbe, among which bacteria was cultured in beef extract-peptone medium; fungus was cultured in Martin medium and actinomycetes was cultured in Improved Gaoshi No.1 medium. The biomass was counted and authenticated by conventional method ${ }^{[8]}$. 


\section{Results and analysis}

Chromatographic detection of phenolic acids

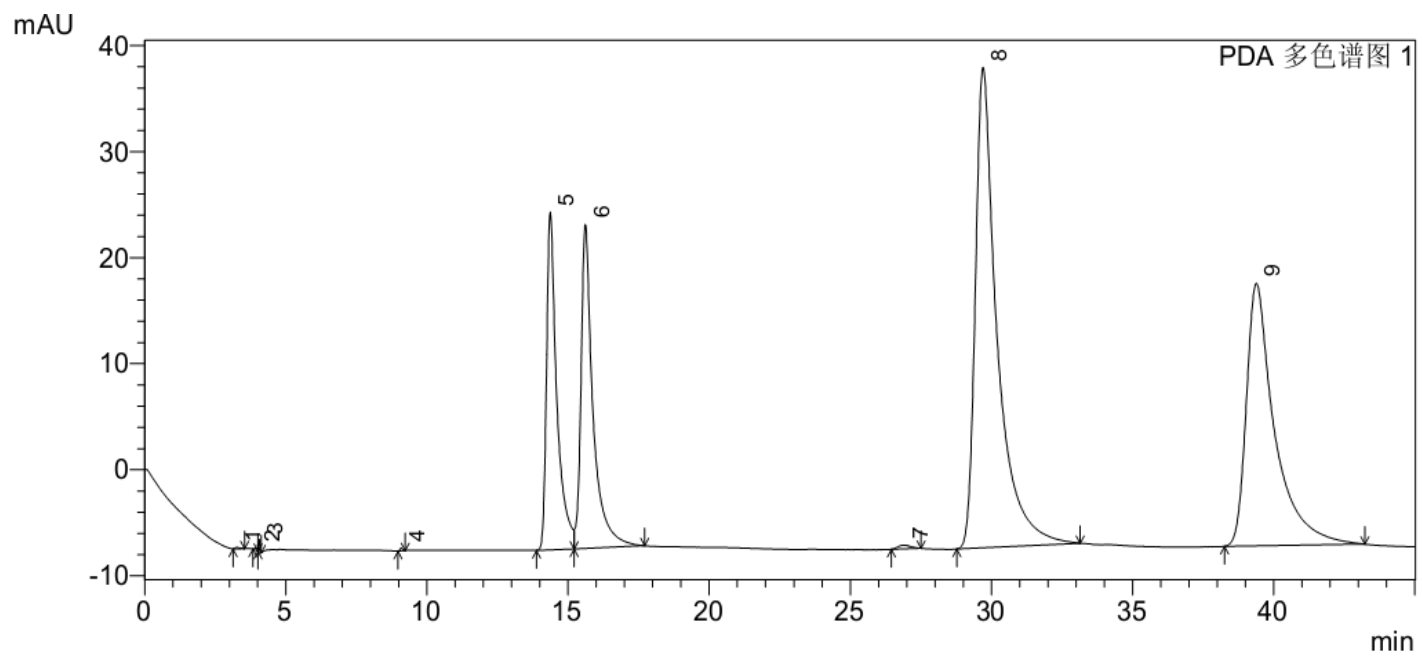

Figure 1. The chromatogram of mixed phenolic acids standard

(Peak 5, 6, 8 and 9 was p-hydroxybenzoic acid, vanillic acid, vanilline and ferulic acid, respectively)

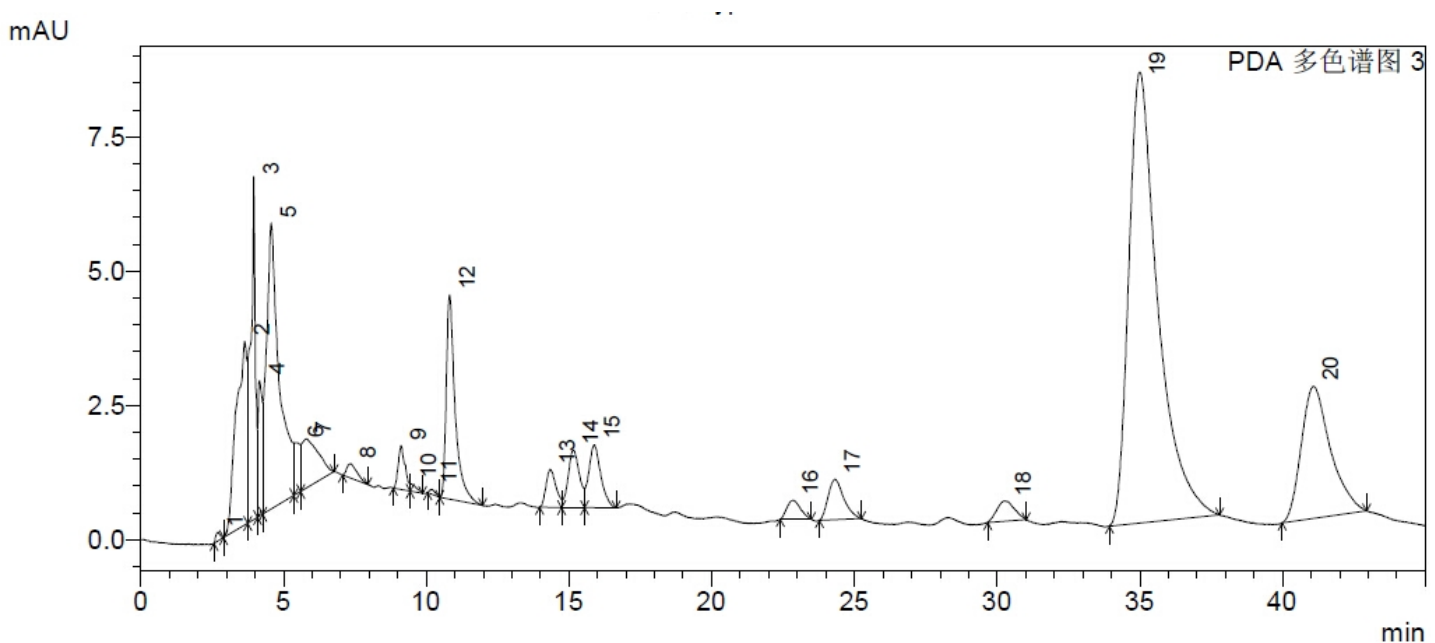

Figure 2. The chromatogram of phenolic acids of soil samples

(Peak 13, 15, 18 and 20 was p-hydroxybenzoic acid, vanillic acid, vanilline and ferulic acid, respectively)

From Figure 2, we could know chromatographic condition above could separate 4 kinds of phenolic acids absolutely, so this condition could be used to determine p-hydroxybenzoic acid, vanillic acid, vanilline and ferulic acid in soils.

Content variation of phenolic acids in soils 
Chart 1. The content of phenolic acids in soils （ug/g）

\begin{tabular}{|c|c|c|c|c|c|c|}
\hline & & PHBA & Vanillic acid & Vanilline & Ferulic acid & $\begin{array}{l}\text { Total } \\
\text { phenolic acids }\end{array}$ \\
\hline \multicolumn{2}{|c|}{$\begin{array}{l}\text { Control } \\
\text { (never crop) }\end{array}$} & 0.13 & 0.17 & 0.00 & 0.33 & 0.63 \\
\hline Crop & Control & 0.19 & 0.30 & 0.11 & 1.26 & 1.86 \\
\hline 1 & Low add & 1.18 & 0.55 & 0.20 & 2.15 & 4.08 \\
\hline year & High add & 2.22 & 1.28 & 0.50 & 5.58 & 9.58 \\
\hline Crop & Control & 0.17 & 0.27 & 0.09 & 0.65 & 1.18 \\
\hline 2 & Low add & 0.31 & 0.48 & 0.25 & 1.47 & 2.51 \\
\hline years & High add & 0.82 & 1.41 & 0.78 & 3.15 & 6.16 \\
\hline
\end{tabular}

Since there were lots of organic acids in wormcast, the content of phenolic acids in the soil would be increased with the increase of wormcast. So the relative amount of 4 kind of phenolic acids could reflect results better.

Chart 2. The relative amount of phenolic acids in soils

\begin{tabular}{|c|c|c|c|c|c|}
\hline & & PHBA & Vanillic acid & Vanilline & Ferulic acid \\
\hline \multicolumn{2}{|c|}{$\begin{array}{l}\text { Control } \\
\text { (never crop) }\end{array}$} & 0.21 & 0.27 & 0.00 & 0.52 \\
\hline Crop & Control & 0.10 & 0.16 & 0.06 & 0.68 \\
\hline 1 & Low add & 0.29 & 0.13 & 0.05 & 0.53 \\
\hline year & High add & 0.23 & 0.13 & 0.05 & 0.58 \\
\hline 二 & Control & 0.14 & 0.23 & 0.08 & 0.55 \\
\hline 茬 & Low add & 0.13 & 0.19 & 0.10 & 0.58 \\
\hline 土 & High add & 0.13 & 0.23 & 0.13 & 0.51 \\
\hline
\end{tabular}

The relative content of vanillic acid, vanilline and ferulic acid were all decreased, but the relative amount of p-hydroxybenzoic acid was firstly increased then decreased with the increase of wormcast in soils cropped Rehmannia glutinosa for one year. And with the increase of wormcast, the relative amount of p-hydroxybenzoic acid and vanilline were decreased and increased respectively, while the vanillic acid relative content was firstly decreased then increased. 
Variation of soil microbe

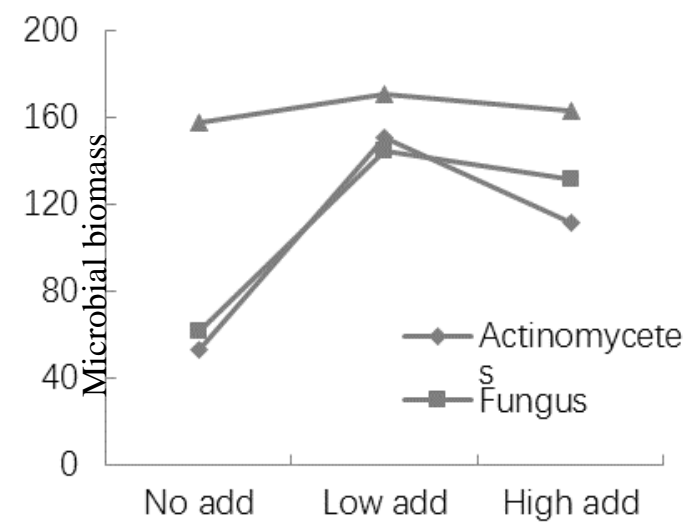

Figure 3. The biomass of 3 kinds of microbe in soils cropped rehmannia for one year

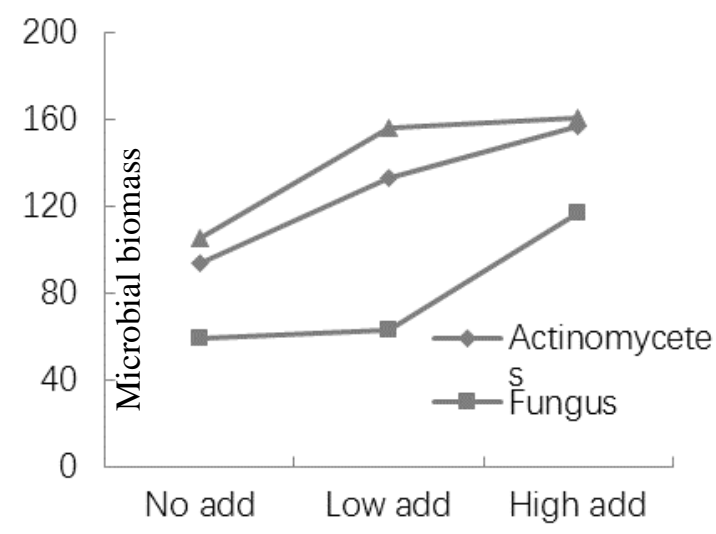

Figure 4. The biomass of 3 kinds of microbe in soils cropped rehmannia for two years

The unit of bacteria and actinomyces is $10^{4}{\mathrm{cuf} . \mathrm{g}^{-1}}^{-1}$ soil, fungus unit is $10^{3}{\mathrm{uf} . \mathrm{g}^{-1}}^{-1}$ soil

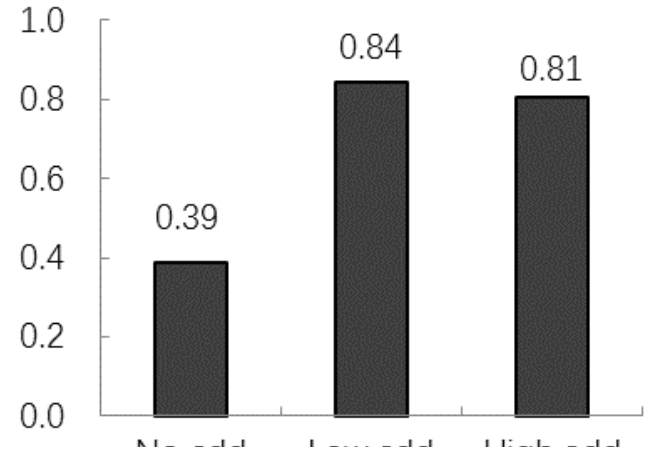

Figure 5. The ratio of fungi to bacteria in soils cropped rehmannia for one year

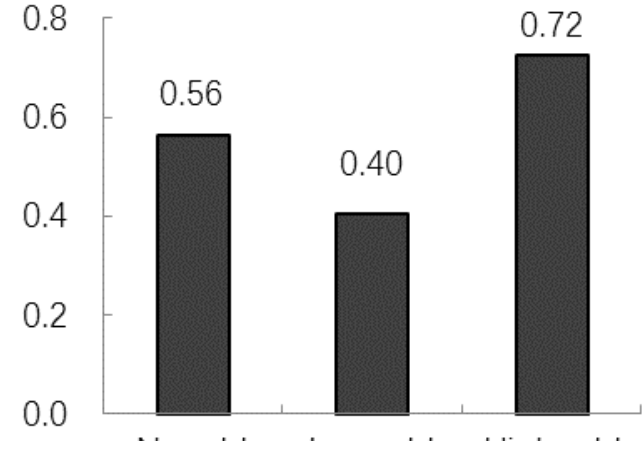

Figure 6. The ratio of fungi to bacteria in soils cropped rehmannia for two years

The amount of microbes were firstly increased then decreased with the increase of wormcast in soils cropped rehmannia for one year, but the general trend was increasing. While in soils cropped rehmannia for two years, the microbes amount were all increased with the increase of wormcast. This indicated that addition of wormcast in soils increased the amount of microbes.

The ratio of fungi to bacteria was increased firstly and then decreased with the increase of wormcast in soils cropped rehmannia for one year, but the general trend was increasing. While the ratio of fungi to bacteria was sharply decreased after added $10 \%$ wormcast and the high addition of wormcast let the result increased sharply.

\section{Discussion}

From the result in this paper, we could get that the content of vanillic acid, vanilline and ferulic acid wereall decreased in the soils cropped rehmannia for one year after addition of wormcast. At the same time, the ratio of fungi to bacteria was increased firstly then decreased in the soils cropped rehmannia for one year after addition of wormcast. However, the result was completely opposite in soils cropped rehmannia for two years.

Rehmannia is one of the plants that have the most serious continuous cropping obstacle. The recent researches of the reasons causes replant diseases were focus on microbial ecological environment in the rehmannia rhizosphere soils and allelochemicals secreted from rehmannia roots. Li's study ${ }^{[10]}$ showed that rehmannia succession cropping would translate edaphon from bacteria domination to fungi domination and the increase of fungus amount would decrease soil fertility definitely. 
Du's research ${ }^{[2]}$ indicated that the key factor effected rehmannia successive cropping obstacle were allelochemicals, mostly phenolic acids, excreted from rehmannia roots. Among which ferulic acid played a major role in the inhibition of rehmannia continuous cropping ${ }^{[11]}$. Because ferulic acid is the prosthetic group of indoleacetic acid oxidase and can improve the IAAO activity and promote the reduction of indoleacetic acid ${ }^{[8,12]}$, which is one of the major endogenous hormone help rehmannia roots grow ${ }^{[13]}$. So, the reduction of phenolic acids content and ratio of fungi to bacteria is helpful to successive cropping obstacle remission.

Study showed that wormcast addition in soils can not only increase the ratio of bacteria to fungus, improve the soil fertility ${ }^{[6]}$, but also can adsorb allelochemicals excrete from plant roots, remove adverse influences causes by allelochemicals, and the meanwhile, some antagonistic microbe in wormcast can restrain the grow of pathogenic bacteria ${ }^{[7]}$. The result of this paper showed that low addition (10\%) of wormcast in soils cropped rehmannia for two years can not only decrease the ratio of fungi to bacteria, improve the microflora, but also maintain phenolic acids content in a reasonable levle half a year, a growth cycle, later, and the effect was the best. But the difference between soils cropped rehmannia for one and two years on microorganism and phenolic acids has to be studied further.

\section{Acknowledgements}

This work was financially supported by Tianjin "131" Talents Engineer Scheme for the First-Level Candidates "Effects of Drought Stress and Mowing disturbance on Competition - Facilitation Interaction of Key Species in Typical Steppe", Scheme for the Excellent Young Teachers of Tianjin Universities "Research on the Alleviate Effect of Exogenous Additives on Continuous Cropping Obstacle of Rehmannia glutinosa", Innovation Teams Scheme of Tianjin Universities "Genetic Improvement of Crops Traits in Qualities and Stress Resistance" (TD12-5017)

\section{References}

[1] Wen XS, Yang SL, Wei JH, et al. Textual research on plan ting history of Rehmannia glutinosa and its cultivated varieties. Chinese Traditional and Herbal Drugs, 2002, 33(10): 946-949 (in chinese)

[2] Du JF. Research of phenolic acids allelopathy on soils around rhizosphere of Rehmannia glutinosa Libosch. Zhengzhou: Henan Agricultural University, 2009 (in chinese)

[3] Chen H, Hao HR, Xiong J, et al. Effects of successive cropping Relmlannia glutinosa on rhizosphere soilm icrobial flora and enzyme activities. Chinese Journal of Applied Ecology, 2007, 18(12):2755-2759 (in chinese)

[4] Liu F, Wen XS, Liu YF, et al. Effect of stachyose on microbiotic disequilibrium in rhizospheric soil of Rehmannia glutinosa. Chinese Traditional and Herbal Drugs, 2007, 38(12): 1871-1874 (in chinese)

[5] Zhang ZY, Chen H, Yang YH, et al. Effects of continuous cropping on bacterial community diversity in rhizosphere soil of Rehmannia glutinosa. Chinese Journal of Applied Ecology, 2010, 21(11): 2843-2848 (in chinese)

[6] Zhang JY, Xu YL, Liu ZQ. Study of the Alleviate of Earthworm Mane on Continuous Copping Obstacle of Cucumber Gowth in Plastic Greenhouse. Northern Horticulture, 2010(4):58-60 (in chinese)

[7] Zhou MR, Sun ZJ, Shen XQ. Research and Application of Earthworm Excrement. Journal of Shanxi Agricultural Sciences, 2012, 40 (8):921-924 (in chinese)

[8] He JH, Fu XB, Ma DM, et al. Changes of Phenolic Acid Content and Rhizosphere Microbial Population in Soil During Tuberous Root Expansion of Rehmannia glutinosa Libosch. HENAN SCIENCE, 2008, 26(11): 1369-1372 (in chinese) 
[9] Zhang SX, Gao ZQ, Liu HL. Continuous cropping obstacle and rhizospheric microecology III. Soil phenolic acids and their biological effect. Chinese Journal of Applied Ecology, 2000, 11(5): 741-744 (in chinese)

[10]Lin ZF, Yang QY, Xie DF, et al. Effects of continuous cropping on the quality of Rehmannia glutinosa L. and soil micro-ecology. Chinese Journal of Eco-Agriculture, 2012, 20(2): 217-224 (in chinese)

[11] Du JF, Yi WJ, Li J, et al. Dynamic change of phenolic acids in soils around rhizosphere of replanted Rehmannia glutinosa. China Journal of Chinese Materia Medica, 2009, 34(8): 948-952 (in chinese)

[12] Du JF, Yi WJ, Zhang ZY, et al. Autotoxicity and phenolic acids content in soils with different plaming interval years of Rehmannia glutinosa. Chinese Journal of Ecology, 2009, 28(3): 445-450 (in chinese)

[13]Xue JP, Ge DY, Zhang AM, et al. Variation of Endogenous Hormones of Tuberous Root of Rehmannia \}glutinosa in vitro. Acta Agronomica Sinica, 2004, 30(10): 1056-1059 (in chinese) 